\title{
Dundee College's Literacy Information Skills Project
}

\author{
Abigail G. Mawhirt
}

\begin{abstract}
In 2009, Dundee College libraries had no formal literacy skills program despite having trained library staff with a variety of abilities and backgrounds. At the same time, the curriculum manager for Special Programs was keen to improve the information and digital literacy skills of specific groups within this area, but was unsure where to find support. Through open discussion with the library team, the possibility of using specialist library skills to develop an information literacy program was considered, with the official launch of the Literacy Information Skills project in the same year.

The project has been very successful in both discrete areas and across the student population. The development of materials for the course has provided a bank of information literacy materials for the College and led to the development of further sessions on a variety of study and soft skills. Outcomes of the project have included both improved literacy skills and improved confidence and social skills.
\end{abstract}

\section{Background - Special Programs at Dundee College}

Students who come to College to join a Special Programs course all qualify for extended learning support due to specific learning difficulties. These students would not be able to participate fully in mainstream curriculum classes as a result of their learning difficulties, often requiring full time or significant one-to-onesupport. Depending on the resources of the local authority, schools may work with these pupils until they are 18/19 years old, but in under-resourced areas it is common for the students to transfer to College where larger departments and trained staff have the ability to provide suitable environments.

Before the Literacy Information Skills project began, it was clear the library at Dundee College was something of a safe haven for students from Special Programs. They spent a great deal of their free time, breaks and lunchtimes in the

\section{Author}

Abigail is the Senior Assistant at Dundee College Learning Hubs, currently a distance learning student undertaking the PG dissertation year for her MA Information and Library Studies.

Email: agmawhirt@gmail.com 
library using computers, chatting with one another and looking at the magazines and comics available. Relationships with library staff were good and the students respected the environment and staff there, regularly popping in for a chat or to share news and achievements.

The students on this program come from a wide variety of backgrounds, many with learning and cognitive issues, others who display challenging behaviour and those from underprivileged backgrounds. Some of the students simply found it hard to fit in at school, disengaged from learning and as a result have lower than average literacy and numeracy skills for their age group. The various reasons for coming to College to attend Special Programs classes mean students are of very mixed of abilities and the classes often encompass students of a reasonably wide age range, mainly 16-21 years of age. While this can seem short in years, the varying social, mental and physical abilities creates a challenging class to deal with, who require significantly differentiated materials.

The College operates in the context of the Curriculum for Excellence, Scotland's new curriculum (Education Scotland, n.d), which replaced the previous curriculum for 5-14 year olds, and for the Standard Grade, Highers and Higher Still qualifications.

The new curriculum is designed to ensure that all school leavers, regardless of age and ability, leave with a recognised qualification proving their skills for learning, life and work.

\section{Literacy Information Skills project}

Once the initial discussion between the curriculum manager and librarian took place, it was then up to the library team to put together a program of tasks, activities and classes that would promote digital and information literacy. As the program is not accredited, the SCQF (Scottish Credit and Qualifications Framework) was required only to gauge the level of understanding and it was more the four pillars of the Curriculum for Excellence (Education Scotland, n.d.) which fed the outcomes of the program, aiming to help students to develop as confident individuals, successful learners, responsible citizens and effective contributors.

The academic year at Dundee College is split into three 12 week blocks. The Literacy Information Skills project ran for 12 weeks per group, so up to three classes could attend in any academic year. The core topics of the course have remained the same and cover:

- How the internet works and online safety / privacy;

- Using Google Earth / Maps and learning about directions and using a map;

- Healthy eating and exercise;

- Weighing and measuring (including weighing ingredients and measuring height);

- Completing a library induction and making a comic strip version of the library user guide; 
- Visiting Waterstone's to choose books for their own library collection.

All the topics were designed to focus on skills for learning, life and work under the new Curriculum for Excellence, incorporating team work, learning to follow instruction, competent use of PC hardware, the internet and how to stay safe online, with every aspect incorporating literacy, numeracy, health and wellbeing or a combination of these.

While the content was designed to cover skills required for life outside College, or as examples for inclusion on applications to further courses, there was a distinct effect on students in their current course. The students became more confident in their abilities, especially when applying their new-found skills to other aspects of their course. They were enjoying the relationship with library staff, further solidifying connections they had started to make when using the library. This was a particularly important aspect of the project, as for many of the students, their only experiences of adults and figures of authority were negative. Many had not found primary and secondary school easy, feeling different or unable to join in and others were constantly reprimanded for difficult or unruly behaviour.

These positive aspects added to the initial driver to improve information literacy and encouraged the project to become a longer term, formalised part of the curriculum for these students.

One of the curriculum areas that Special Programs has close links with is Hospitality, as many students progress into this area. This opened up discussions into tailoring the Literacy Information Skills project for a Hospitality group, as many students from basic hospitality courses were struggling to complete coursework due to low levels of literacy and numeracy.

\section{Hospitality Information Skills project}

In 2010, a second stream of students began attending the library to improve their information literacy as part of the project, this time Hospitality students. The basis of the topics was similar, as was the aim: to improve the information and digital literacy of the students attending, allowing them to integrate better and to succeed on their course of study. Topics included:

- Online safety and finding reliable online information;

- Healthy Eating and Exercise;

- Healthy foods - the Eatwell plate;

- Following recipes by following instruction and knowing weights and measures (including practice measuring and learning about measurements);

- Creating a class recipe book from creating and choosing the recipes, to sourcing images, selecting a name for the book and creating it in Microsoft Office programs;

- Using the library catalogue to find cookery books, select some based on their interests and then borrow them; 
- Using online resources to find relevant e-books and watch cookery programs online.

For both groups, the materials were developed using reliable resources including BBC materials. This was coupled with close work with curriculum staff to ensure tasks were at a suitable level and providing valuable skills required to fully partake in their curriculum classes. Once agreed and finalised, these were put into a course on the College's virtual learning environment (VLE) - originally Blackboard and now Moodle - to ensure the inclusivity so very important to these learners.

The creation of their own course in the VLE allowed them to feel like all the other students in the College, accessing learning materials through the VLE, but at the same time giving them ownership. This is their course and materials, designed for them and often dictated by them. The students enjoyed a competitive aspect to activities and particularly being split into teams, keeping running scores. Moodle has an option of tick boxes so students can tick off the activities they have completed and this in itself proved very popular, creating a sense of empowerment and ownership.

When tasks and activities were finished in good time, students would be able to choose from extension activities. These would be designed to seem fun whilst actually working on improving information literacy. Examples included:

- QR (Quick Response) code treasure hunt - a new take on finding information in the library by scanning a series of QR codes to find clues. Questions can be general knowledge, something to search for, specific classifications or number and word games. A QR code is a special type of barcode which can be scanned using a smartphone to open a link to website address encoded into the QR code.

- Using iPads to search for answers to questions improving online research skills, to browse the library catalogue and search for classification numbers / titles / authors etc., complete quizzes - all of which become fun and interesting when an iPad is used rather than a standard College PC.

These tasks allowed students to make informed decisions on information available, developing their quality versus quantity judgements, how reliable a source of information is and promoted good practice in information literacy.

\section{AccessApps}

Alongside these classes, the SLIC (Scottish Library and Information Council) Innovation and Development Funded PADDI (Portable Access Device Development Initiative) Project took place. The project was delivered in conjunction with the JISC Regional Support Centre and aimed to create a Dundee College-specific suite of the pre-existing AccessApps assistive technology tools available to the whole College population.

The outcome of the project was the installation of the suite of tools onto every Dundee College networked PC and branded Dundee College memory pens available for anyone wishing to make use of the tools off-network. The suite 
included onscreen reading rulers and overlays, a conversion tool, a magnifying glass, a mouse pointer tool for higher visibility and a typing program, along with links to the library podcast, comic strip guide and online induction.

For each of the Literacy Skills groups there was a class devoted to looking at these apps and explaining their use and benefits. This was surprisingly successful in terms of improved literacy, as in many cases the coloured overlays or reading rulers provided a genuine improvement for reading onscreen, but they were also deemed cool and fun which also encouraged reading online information.

\section{Outcomes of the Literacy Information Skills Project}

For everyone involved in the project there was a beneficial outcome. For the library staff, there was an opportunity to work with specific groups of learners, using their specialised skills to improve student engagement, information literacy and numeracy. Library staff also have a bank of high quality materials ready for use with any group or individual to improve digital and information literacy. For staff in curriculum areas, time to teach core subjects is very precious so the work of the library team to improve the students' literacy skills made a huge difference in terms of subject ability. The classes were also delivered in the library instead of the department, allowing curriculum staff to focus on their key subject issues whilst sure the students were with specialist staff who were using good quality materials.

Most importantly, the benefits to the students themselves were manifold. The key outcome had always been to improve the information literacy of the students and this was delivered. This was assessed with a focus group at the end of the course of study, where students indicated what they had learnt, where they felt more confident and how they felt the skills were relevant. However, the project also instilled confidence and subsequently improved social skills and interaction with a wider College population. These skills are much harder to impart, but with improved understanding of core subjects and the ability to show others new skills, confidence became a natural by-product.

\section{Information Literacy at Dundee College - What Next?}

The implementation of the Literacy Information Skills classes along with the versatile bank of materials required has raised the library profile within College, along with the skills of the staff. The course and materials are ready to be used with any individual or group and the possibility of accrediting some of the material for use in the curriculum or delivery through the library is under investigation.

Since developing the Literacy Information Skills materials, library staff have also developed a beginners' guide to the internet and online tools, a very comprehensive referencing guide and a study skills guide. Each of these has been designed to include a hard copy booklet which is professionally printed, an interactive online guide made using Wimba Create - an add-in for Microsoft Word, which allows Word documents to be transformed into interactive webpages simply and quickly - and a stand-alone hour long session delivered by library staff. The good practice already demonstrated is set to continue with increased 
curriculum links through delivering our materials to more learners across the College.

\section{Reference}

Education Scotland (n.d.). What is Curriculum for Excellence? URL:

http://www.educationscotland.gov.uk/thecurriculum/whatiscurriculumforexcellen ce/index.asp [accessed 18.03.13].

\section{Open access and copyright}

Library and Information Research is an open access journal. A freely available copy of this paper may be downloaded from the journal's website:

http://www.cilipjournals.org.uk/lir

Copyright and associated moral rights in works published in Library and Information Research are retained by the author(s) but this paper may be used freely, with proper attribution, in educational and other non-commercial settings. 